\title{
Stage IA Fallopian Tube Cancer AJCC v6 and $v 7$
}

National Cancer Institute

\section{Source}

National Cancer Institute. Stage IA Fallopian Tube Cancer A/CC v6 and v7. NCI Thesaurus. Code C6269.

Stage IA includes: T1a, N0, M0. T1a: Tumor limited to one tube, without penetrating the serosal surface; no ascites. N0: No regional lymph node metastasis. M0: No distant metastasis. (AJCC 6th and 7th eds.) 